\title{
Perfil da fluência de indivíduos com taquifemia*****
}

\author{
Speech fluency profile in cluttering individuals
}

\author{
Cristiane Moço Canhetti de Oliveira* \\ Ana Paula Lazarin Bernardes** \\ Gabriela Aparecida Fabbri Broglio*** \\ Simone Aparecida Capellini****
}

\begin{abstract}
*Fonoaudióloga. Doutora em Ciências Biológicas na Área de Genética pelo Instituto de Biociências da

Universidade Estadual Paulista

(Unesp) de Botucatu (SP). Docente do Departamento de Fonoaudiologia da Faculdade de Filosofia e Ciências da Unesp de Marília (SP). Endereço para correspondência: Av. Hygino Muzzi Filho, 737 - Marília -SP - CEP 17525000 (cmcoliveira@marilia.unesp.br).
\end{abstract}

**Fonoaudióloga pela Unesp de Marília (SP).

***Fonoaudióloga. Discente do Curso de Fonoaudiologia da Unesp de Marília (SP).

****Fonoaudióloga. Doutora em Ciências Médicas pela Faculdade de Ciências Médicas de Campinas (SP).

Docente do Departamento de Fonoaudiologia e Programa de PósGraduação em Educação da Faculdade de Filosofia e Ciências da Unesp de Marília (SP).

*****Trabalho Realizado no Departamento de Fonoaudiologia da Faculdade de Filosofia e Ciências Unesp de Marília - SP.

Artigo Original de Pesquisa

Artigo Submetido a Avaliação por Pares

Conflito de Interesse: não

\begin{abstract}
Background: speech fluency in cluttering. Aim: to characterize and to compare the speech fluency in cluttering and fluent individuals. Method: participants of this investigation were 14 individuals with ages between 8.0 and 40.11 years, of both genders, divided into two groups, paired by age and gender. GI was composed by 7 cluttering individuals and GII by 7 fluent individuals. The Speech Fluency Assessment Protocol was used to gather and to analyze the speech samples, taking into consideration the typology and frequency of speech disruption (SLD and OD) and speech rate, in words and syllables per minute. Results: data showed that the groups differed regarding the occurrence of the stuttering-like disfluencies and other disfluencies, number of words and syllables per minute. Conclusion: cluttering individuals present a different fluency profile when compared to their fluent pairs.
\end{abstract}

Key Words: Speech, Language and Hearing Sciences ; Speech; Diagnosis.

\section{Resumo}

Tema: fluência na taquifemia. Objetivo: caracterizar e comparar a fluência de indivíduos com taquifemia com indivíduos fluentes. Métodos: participaram dessa investigação 14 indivíduos na faixa etária de 8.0 a 40.11 anos de idade, de ambos os gêneros divididos em dois grupos, pareados por idade e gênero. GI foi composto por 7 indivíduos com taquifemia e GII por 7 indivíduos controles. Um protocolo de avaliação da fluência da fala foi utilizado para obter e analisar a amostra de fala, que considera a tipologia, a freqüência das disfluências e a velocidade de fala. Resultados: os dados indicaram que os grupos se diferenciaram em relação às disfluências comuns e gagas, número de sílabas e de palavras por minuto. Conclusão: o perfil da fluência de indivíduos com taquifemia é muito distinto do perfil de falantes fluentes. Palavras-Chave: Fonoaudiologia; Fala; Diagnóstico 


\section{Introduction}

Cluttering is a fluency disorder wherein segments of conversation in the speaker's native language are typically perceived as too fast overall, too irregular, or both. The segments of rapid and/ or irregular speech rate must further be followed by one or more of the following symptoms: excessive "normal" disfluencies (more than 8-10\%), omission of syllables and/or pauses, abnormal syllable stress or speech rhythm [1].

The speech fluency profile in cluttering individuals is of extreme relevance in both scientific and clinical areas since it allows characterizing the typology and the frequency of speech disruption and the speech rate. These measurements are used like diagnostic criteria of the different fluency disorders, providing more credibility and better control of the effectiveness of the treatment.

The raise of speech rate may cause imprecise articulation, omission of pauses, an excessive number of other disfluencies, inappropriate prosody, as well as reduced speech intelligibility. The communication of a cluttering individual is impairment in several areas as pragmatics, oral language, writing language, speech and motor skills [2].

Objective and substantial descriptions comprising data on fluency of cluttering individuals are few. So, it becomes important to investigate the speech fluency profile in cluttering individuals, through the Speech Fluency Assessment Protocol [3] direct to characterize objectively necessary measures for defining the diagnostic and therapeutic planning. The purpose of the present investigation was therefore to characterize and to compare the fluency speech in cluttering and fluent individuals.

\section{Method}

Participants

This study started after the approval of the Institution's Ethics Committee in Research of Universidade Estadual Paulista - FFC - Marília (protocol number 3491/2008), and permission of the patient when adult or of the keepers when infants or teenagers.

Participants of this study were 14 individuals between 8.0 and 40.11 years old (mean age of 34:5 years), of both gender ( 8 female and 6 male) divided in two groups, paired by age and gender.
The research group (GI) consisted of 7 cluttering individuals with no other associated communicative, neurologic and cognitive deficit. A multiple criteria was used on the cluttering diagnostic: (a) speech disorder complaint (fast speech rate) on the part of the parents in case infants or teenagers, or by the individuals themselves if adults; (b) to be considered as clutterer by the researchers; (c) present at least $10 \%$ of the other disfluencies (OD), and: (d) speech rate outside the references values for age and gender [4].

The control group (GII) consisted of 7 fluent individuals, with no disfluency complaints (current or former) on the part of families, teachers or individuals themselves, and with no communicative, neurologic and cognitive deficits according to collected data. The inclusions criteria of the participants of GII were: (a) show less than $10 \%$ of other disfluencies (OD) and less than 3\% of stuttering-like disfluencies (SLD); (b) no family history of cluttering and stuttering.

\section{Procedures}

In order to obtain the research data was used the Speech Fluency Assessment Protocol [3] to characterize the typology, the frequency of speech disruptions and the speech rate. A speech sample of each participant contained at least 200 fluent syllables was collected from a visual stimulus of picture. The individual speech could only be interrupted (with questions and comments) in cases that an incentive for production was necessary in order to achieve the minimal number of syllables to permit an analysis.

Each conversational sample was recorded for analysis and comparison of the findings, using a SONY Digital Handycam and tripod.

After collecting speeches of the participants, a transcript was made, considering both fluent and non-fluent syllables. Later, it was made the analysis of speech sample and categorized the typology of the disfluencies, consistent with the following description:

. Other disfluencies (OD): hesitation, interjections, revisions, unfinished word, word repetition, segment repetition and phrase repetition.

. Stuttering-like disfluencies (SLD): syllable repetition, sound repetition, prolongation, block, pauses and intrusion of sound or segments. 
For characterizer the frequency of speech disruptions, the following measurements were used: percentage of other disfluencies (OD) and percentage of stuttering-like disfluencies (SLD). The speech rate was measured according to the used protocol, characterizing the flow of syllables and words per minute (SPM, WPM) [3].

The collect data were subjected to statistics analysis, through the application of the MannWhitney Test, aiming at verifying possible differences among the studied groups, to the variables of interest. The Friedman Test was applied for verifying possible differences among the analyzed variables, by studied group (intergroup). For this research, the adopted level of significance was of $\mathrm{p}=0.05$ (5\%). The significant results were marked with asterisks.

\section{Results}

The results are presented in the Tables 1, 2 and 3. There was statistically significant difference between the groups for the four measurements analyzed (other disfluencies - OD, stuttering-like disfluencies - SLD, flow of syllables and words per minute - SPM, WPM). GI showed approximately twice the number of other and stuttering-like disfluencies, and an increase in flow of syllables and words per minute when compared to GII (Table 1).

The occurrence of other disfluencies (OD) of the participants groups is distributed according to their typologies on Table 2. No differences were found between the two groups on the amount of hesitation and segment repetition. However, GI showed more than twice the number of interjection, revision and unfinished word than GII. GI produced seven times more word repetition when compared to GII.

The most common typology was interjection for GI, and hesitation for GII. Both groups presented on average less occurrence of the typology unfinished word and they didn't present the typology phrase repetition.
For both GI and GII there was statistically significant difference on the occurrence of other disfluencies (OD). The Wilcoxon Test showed statistically significant difference for the following other disfluencies obtained from GI: hesitation x unfinished word and segment repetition; interjection $\mathrm{x}$ unfinished word, segment repetition and word repetition; revision $\mathrm{x}$ unfinished word and segment repetition.

The Wilcoxon Test showed statistically significant difference for the following other disfluencies obtained from GII: hesitation $\mathrm{x}$ revision, unfinished word, segment repetition and word repetition; interjection $\mathrm{x}$ revision, unfinished word, segment repetition and word repetition; revision $\mathrm{x}$ unfinished word.

In order to compare both groups, each type of speech disruption was analyzed apart. The results indicated that there was no statistically significant difference between the groups concerning the number of hesitation, unfinished word and segment repetition. The typologies interjection, revision and word repetition were statistically significant different between the groups, showing higher occurrence in the GI.

The table 3 presents the results regarding the occurrence of stuttering-like disfluencies (SLD) of the participants distributed according to their typologies. The data showed a tendency in GI present higher number of stuttering-like disfluencies (sound repetition, prolongation, block and intrusion). For both GI and GII the average of occurrences on the typology stuttering-like disfluencies (SLD) indicated no significant statistical differences.

Prolongation was the typology of higher occurrence for GI whereas syllable repetition and prolongation were for GII. Both GI and GII haven't showed the typology pause.

In the inter-group comparison of the analysis of each typology apart, it is noticed that no typology showed statistically significant differences. 
TABLE 1.Inter-group comparison concerning other and stuttering-like disfluencies events, flow of syllables and words per minute.

\begin{tabular}{|c|c|c|c|c|c|c|}
\hline Variable & Group & Mean & SD & Minimum & Maximum & $\begin{array}{l}\text { Analysis inter-group } \\
\text { p-value - Mann-Whitney }\end{array}$ \\
\hline \multirow[t]{2}{*}{ Other disfluen cies (OD) } & GI & 12,57 & 1,82 & 9,00 & 15,00 & \multirow[t]{2}{*}{$<0,001^{*}$} \\
\hline & GII & 5,64 & 1,97 & 3,00 & 10,00 & \\
\hline Stuttering-like & GI & 0,57 & 0,55 & 0,00 & 2,00 & \multirow[t]{2}{*}{$0,049 *$} \\
\hline disfluencies (SLD) & GII & 0,21 & 0,43 & 0,00 & 2,00 & \\
\hline Syllables per minute & GI & 295,28 & 53,16 & 213,00 & 375,10 & \multirow[t]{2}{*}{$0,034^{*}$} \\
\hline$(\mathrm{SPM})$ & GII & 247,62 & 48,51 & 153,85 & 315,79 & \\
\hline Words per minute & GI & 179,46 & 26,30 & 150,00 & 257,14 & \multirow[t]{2}{*}{$0,001^{*}$} \\
\hline (WPM) & GII & 141,35 & 27,57 & 89,23 & 180,00 & \\
\hline
\end{tabular}

Legend: SD, standard deviation.

TABLE 2. Intra and inter-group s comparison concerning the typology of other disfluencies (OD).

Hesitation Interjection Revision Unfinished word Segment repetition Word repetition p-value

Friedman

\begin{tabular}{cccccccccccccc}
\hline M & DP & M & DP & M & DP & M & DP & M & DP & M & DP & \\
4,93 & 2,46 & 10,79 & 4,58 & 4,14 & 2,32 & 0,43 & 0,85 & 0,50 & 0,86 & 3,64 & 2,56 & $<0,001 *$ \\
4,64 & 2,21 & 3,86 & 2,03 & 1,57 & 0,94 & 0,21 & 0,43 & 0,43 & 0,65 & 0,50 & 0,65 & $<0,001 *$ \\
\hline
\end{tabular}

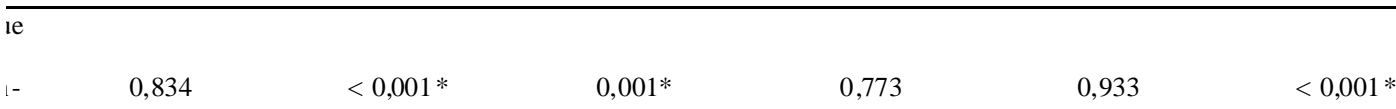

ey

Legend: M, mean; SD, standard deviation.

TABLE 3. Intra and inter-groups comparison concerning syllable repetition, sound repetition, prolongation, block, pause and intrusion.

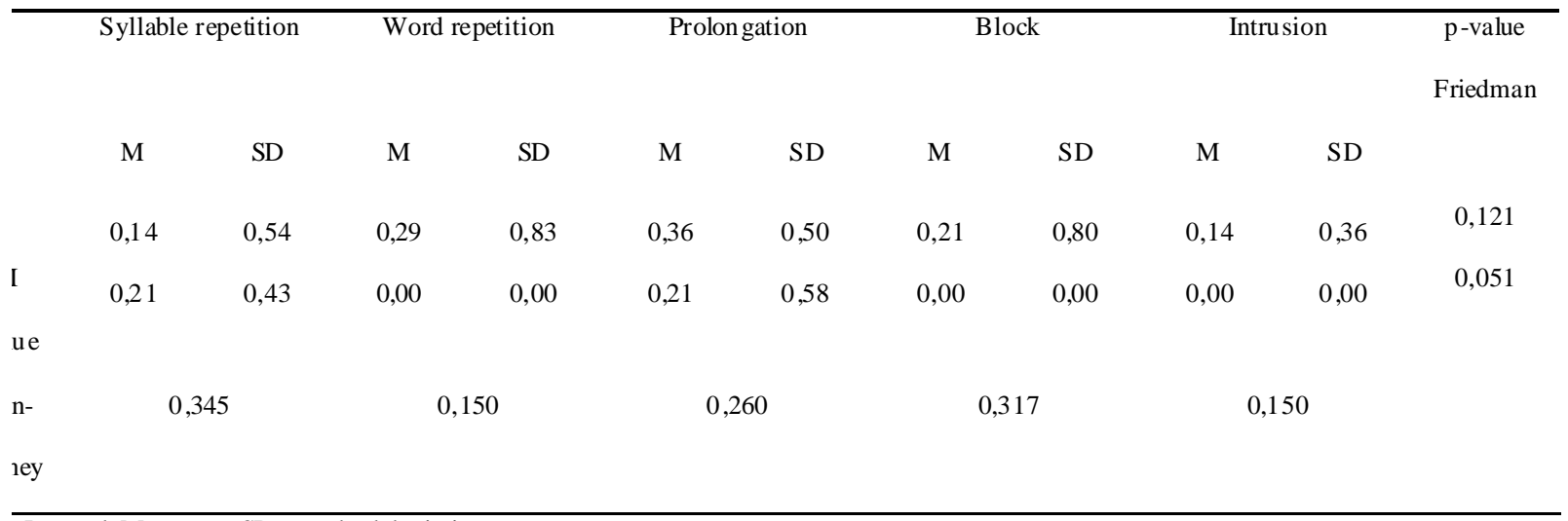

Legend: M, mean; SD, standard deviation. 


\section{Discussion}

As pointed in the literature [1-2,5-6] the presence of excessive other disfluencies is one of the most essential symptom of cluttering. The analysis of the typology of other disfluencies (OD) indicated that GI presented twice more interjections, revisions, unfinished words and word repetitions than GII. Our findings agree with a study [7] that has found interjections, revisions and unfinished word, as well more frequently disfluencies in the speech of two cluttering individuals.

The fast speech rate or possible language difficulties may justify the mentioned increase on the amount of other disfluencies (OD). Despite the literature [2,5-8] highlights the presence of other disfluencies, the analysis of the typology of the clutterers has been little explored so far [7].

For the fluent individuals, the hesitation was the typology of other disfluencies of higher occurrence, confirming previous studies [9] (Juste and Andrade, 2006).

The frequency of stuttering-like disfluencies (SLD) for the two groups was low, as already expected, considering the fact that this typology is typical in persons who stutter (PWS) [10,11,12]. However, the results showed that GI presented more than twice stuttering-like disfluencies (SLD) when compared with GII.

For the cluttering group, the stuttering-like disfluency of higher occurrence was the prolongation. Concerning the fluent group, prolongation and the syllable repetition were the only stuttering-like disfluencies that occurred. The prolongation was most common the speech disruption in a study of a fluent children group [13]. In other study with speakers of Brazilian

\section{References}

1. St. Louis KO. Global perspectives on cluttering: research, assessment and treatment. Paper presented at the 6th World Congress on Fluency Disorders, Rio de Janeiro, Brasil. 2009.

2. Daly DA, Burnett ML. Cluttering: assessment, treatment planning, and cause study illustration. J Fluency Disord. 1996;21:239-48.

3. Andrade CRF. Protocolo para avaliação da fluência da fala. Pró-Fono. 2000;12(2):131-4.

4. Andrade CRF, Martins VO. Perfil evolutivo da fluência da fala de falantes do português brasileiro. Pró-Fono. 2008;20(1):7-13.

5. Myers FL. Cluttering: a matter of perspective. J Fluency Disord. 1996;21:175-85.
Portuguese [9] the prolongation and the pause were the typologies of higher occurrence in fluent children.

The cluttering group showed an increase in the flow of syllables per minute (SPM) as well as in the flow of the words per minute (WPM), corroborating previous studies [2, 6, 8, 14]. This increase in the speech rate may cause the increase in the amount of both the other disfluencies (OD) and the stuttering-like disfluencies (SLD), considering the complexity of the production of the speech. The reduced temporal margin for processing the message and performing the motor movements of the speech possibly causes impaired in the fluency, articulation, prosody, and consequently in the speech intelligibility.

It is important to highlight that the irregular speech rate is one of the characteristics of cluttering. This fact impaired the fluency assessment, since during the recording of the speech, the clutterer generally controls his/her speech and so, he/she doesn't show a fast speech rate as it normally occurs during conversations. Perhaps, for this reason, the measures of flow of syllables per minute and words per minute are not so increased in relation to the fluent group.

\section{Conclusion}

This study represents a first attempt to characterize the fluency profile of cluttering individuals. The results indicate that a significant statistical difference exists between the cluttering and fluent group for the other and stuttering-like disfluencies (OD and SLD), flow of syllables and words per minute (SPM and WPM). Therefore, the fluency profile of cluttering individuals is very different of the fluency profile of fluent individuals.
6. ASHA. Special Interest Division 4: Fluency and Fluency Disorders (1999, march). Terminology pertaining to fluency and fluency disorders: Guidelines. Asha. 1999.41(Suppl), 29-36.

7. Myers FL, St Louis KO. Two youths who clutter, but is that the only similarity? J Fluency Disord. 1996;21:297304.

8. Starkweather CW. The assessment of fluency. In: National Institute on Deafness and Other Communication Disorders: Assessment of Speech and Voice Production: Research and Clinical Applications. Proceedings, Bethesda. 1991;1:215.

9. Juste F, Andrade CRF. Tipologia das rupturas de fala e classes gramaticais em crianças gagas e fluentes. Pró-Fono. 2006;18(2):129-40. 
10. Yairi E, Ambrose NG, Paden EP, Throneburg RN. Predictive factors of persistence and recovery: pathways of childhood stuttering. J Commun Disord. 1996;29:5177.

11. Sawyer J, Yairi E. The effect of sample size on the assessment of stuttering severity. American. J Speech Lang Pathol. 2006;15(1):36-44.

12. Wittke-Thompson JK, Ambrose N, Yairi EC, Cook $\mathrm{EH}$, Ober C. et al. Genetic studies of stuttering in a founder population. J Fluency Disord. 2007;32:33-50.
13. Carlo EJ, Watson JB. Disfluencies of 3- and 5- years old Spanish-speaking children. J Fluency Disord. 2003; 28:37-53.

14. St. Louis KO, Myers FL. Clinical management of cluttering. Lang Speech Hear Services School, 1996; 26:187-95. 